\begin{tabular}{c} 
International Journal of Biological Research, $4(2)(2016) 307-317$ \\
International Journal of Biological Research \\
SPC \\
Website: $\begin{array}{c}\text { www.sciencepubco.com/index.php/IJBR } \\
\text { doi: } 10.14419 / j b r . v 4 i 2.6867 \\
\text { Research paper }\end{array}$ \\
\hline
\end{tabular}

\title{
Plasmid Profile of Multiple Antibiotics Resistant (mar) Escherichia coli, Pseudomonas aeruginosa and Staphylococcus aureus Isolated from Water Samples from Ebira Communities in Ekiti South Senatorial District
}

\author{
Odeyemi, Adebowale Toba*., Oluwole, Olusola Adeoye., Iseyemi, Seyifunmi and Ohunayo, Adeniyi Success \\ Microbiology Department, Ekiti State University, Ado-Ekiti, Ekiti State, Nigeria \\ *Corresponding author E-mail: adebowaleodeyemi@gmail.com
}

\begin{abstract}
Plasmid curing of microbes and physicochemical analysis of water samples obtained from Ebira communities in six local governments in Ekiti South Senatorial District were analyzed. Antibiotic sensitivity and profile of bacterial isolates were analyzed using pour plating, disk diffusion method and gel electrophoresis techniques respectively while the plasmid were cured using acridine orange. The mean total bacterial count of the water samples collected from these six different local governments at different time ranged from $2.08 \mathrm{x} 10^{5}$ to $6.0 \times 10^{6} \mathrm{CFU} / \mathrm{ml}$; the mean total coliform count ranged from $2.41 \times 10^{5}$ to $3.75 \times 10^{6} \mathrm{CFU} / \mathrm{ml}$ and the mean total Escherichia coli count (TEC) ranged from $1.53 \times 10^{5}$ to $3.45 \times 10^{5} \mathrm{CFU} / \mathrm{ml}$. Total of 152 bacteria were recovered with E.coli having the highest distribution of $35 \%$ while Serratia marcensens had the least distribution of $0.7 \%$. The highest antibiotic resistance of $100 \%$ was recorded against ceftazidine but only $17 \%$ of the isolates were resistant to gentamicin. About $56 \%$ of 34 selected MAR isolates carried plasmid(s) with high molecular weight ranging from $5.64 \mathrm{Kbp}$ to $23.13 \mathrm{Kbp}$. Antibiotic resistance pattern and plasmids profile of selected MAR E.coli, Pseudomonas aeruginosa and Staphylococcus aureus prior to and after curing showed that Pseudomonas aeruginosa became susceptible to augmentin and Staphylococcus aureus also became susceptible to ceftriazole while E. coli still maintained the earlier resistant pattern. The plasmid profiling of these isolates after curing indicated the lost of plasmids in each of the isolates. Present study however implicated the incidence of MAR bacteria in the sources of water in Ekiti-South Senatorial district as a serious health challenge, and confirmed the potential of acridine orange for plasmid curing.
\end{abstract}

Keywords: Plasmid Curing; Ekiti South Senatorial District; MAR; Acridine Orange.

\section{Introduction}

With growing populations and an overall increase in living standards, not only is the overall demand for freshwater pushing limits, but increasing pollution from urban, industrial, and agricultural sources is also making available resources either unusable or dangerous to health (Figueras and Borrego, 2010). Water stress occurs when the demand for water exceeds the available amount during a certain period or when poor quality restricts its use. Water stress causes deterioration of freshwater resources in terms of quantity (aquifer over-exploitation, dry rivers, etc.) and quality (eutrophication, organic matter pollution, saline intrusion etc.).

Every human needs about 20 litres of freshwater a day for basic survival (drinking and cooking) and an additional 50 to 150 litres for basic household use. Rural communities around the world traditionally take their water supply from rivers or from shallow dug wells. Growing concentrations of people combined with the increasing industrialization of land use have resulted in many major rivers becoming highly polluted. Key pollutants in the water systems are typically pathogens arising from human waste (bacteria and viruses), heavy metals, and organic chemicals from industrial waste. Water pollution is one of the greatest causes of mortal- ity that can be linked to environmental factors. Almost five million deaths in the developing world annually are due to waterrelated diseases.

This research focused on incidence of MAR bacteria among the microbial isolates from the leachate contaminated water sources from Ebira communities in Ekiti South Senatorial district of Ekiti State, Nigeria. In addition potency of acridine orange as plasmid curing agent would be evaluated.

\section{Materials and methods}

\subsection{Sampling sites}

Water samples were collected from various communities in six local government areas from Ekiti South Senatorial district in Ekiti State comprising Ekiti East, Ekiti South West, Emure, Gbonyin, Ikere and Ise/Orun. The sampling points are: Aba Ola, Aba Afolu, Aba Oyo, Eporo, Ijaloke, Aba Isua, Kajola, Araromi, Ikere Ekiti, Aisegba Ekiti, Ogotun Ekiti, Ijan Ekiti, Ilumoba Ekiti, Igbara-odo Ekiti, Edugbe, Erinta, Iworo. 


\subsection{Collection of water samples}

Water samples were collected aseptically in $250 \mathrm{ml}$ sterile sampling bottles and they were collected from three different sources well (W), stream (S), borehole (B). The samples were transported in ice-bag to the Microbiology Laboratory of Ekiti State University, Ado-Ekiti and were subjected to immediate analysis within two hours of sample collection.

\subsection{Microbiological analysis}

The water samples were analyzed on different culture media using the standard pour plate technique. Nutrient agar was used for the heterotrophic plate count; Eosin Methylene Blue (EMB) for the isolation of Escherichia coli, mannitol salt agar (MSA), for the isolation of Staphylococcus aureus, MacConkey agar for Enterobacter and other coliforms (APHA, 1998). Colonies with distinct characteristics on each culture medium were identified on the basis of their morphological, sugar fermentation and biochemical properties using the scheme in the Bergey's manual of Determinative Bacteriology (Holt et al., 1994).

\subsubsection{Antibiotic susceptibility test}

Inocula for standard antimicrobial susceptibility tests were prepared by touching four to five similar colonies of Gram-positive or Gram-negative bacteria with a loop, transferring these colonies to tryptic soy broth, and incubating them at $35^{\circ} \mathrm{C}$ for 2 to $5 \mathrm{~h}$ until the turbidity was equivalent to a $0.5 \mathrm{BaSO}_{4}$ standard. Suspensions in tryptic soy broth equivalent to a $\mathrm{BaSO}_{4}$ standard were prepared from a $24 \mathrm{~h}$ culture plate of the fastidious organisms.

Colony counts were performed on each inoculum by subculturing various dilutions of the inocula in water. A $0.1 \mathrm{ml}$ volume of each dilution was subcultured onto an appropriate agar plate, spread with a sterile glass rod, incubated for 24 to $48 \mathrm{~h}$ at $35^{\circ} \mathrm{C}$, and counted with a Fisher bacterial colony counter, model 480 .

Antibiotic susceptibility was done using the disc diffusion method for each of the isolate as described by Cheesbrough (2006). The antibiotics used were; cefotaxime (CAZ $3 \mu \mathrm{g}$ ), cefuroxime (CRX

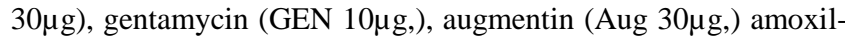

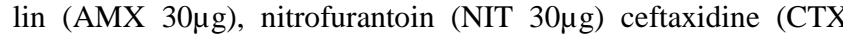
$30 \mu \mathrm{g}$ ), ofloxacin (OFL $5 \mu \mathrm{g}$ ). The diameter of zone of the clearance including the diameter of the disk was measured to the nearest whole millimeter and interpreted on the basis of CLSI (2005) guidelines.

\subsubsection{Isolation of plasmid DNA and agarose gel electrophore- sis}

The multiple antibiotics resistant (MAR) isolates of Salmonella species and the antibiotic sensitive Salmonella species isolates were subjected to plasmid DNA isolation according to the protocol of Birnboim and Doly (1979); Kado and Liu (1981) with some modifications. Agarose gel electrophoresis of the isolated plasmid DNA was carried out in tris-borate buffer system, using $1.2 \%$ agarose, for $1 \mathrm{~h}$ at $75 \mathrm{v}$.

a) The plasmids DNA were isolated using lysing solution.

The lysate were kept in ice for $30 \mathrm{~min}$ and centrifuged for $5 \mathrm{~min}$, phenol: chloroform (1:1) treatment was followed with the clear supernatant. Plasmid DNA were precipitated with equal volume of chilled isopropyl alcohol and DNA pellet dissolved in $100 \mu \mathrm{l}$ of TE buffer (diethylether).

b) A $0.8 \%$ agarose gel was used to resolve DNA fragment and it was prepared by combining $0.8 \mathrm{~g}$ agarose in ten times concentration of Tris acetate ethylene diamine tetraacetate $(10 \mathrm{ml} 10 \mathrm{XTAE})$ buffer and $90 \mathrm{ml}$ distilled water in a $250 \mathrm{ml}$ beaker flask and heating in a microwave for $2 \mathrm{~min}$ until the agarose is dissolved. $2.5 \mathrm{ml}$ ethidium bromide $(5.0 \mathrm{mg} / \mathrm{ml})$ was added to the dissolved agarose solution with swirling to mix. The gel was then poured onto a mini horizontal gel electrophoresis tank and the casting combs were inserted. It was then allowed to gel for $30 \mathrm{~min}$. The casting comb was then carefully removed after the gel had completely solidified. One times concentration (IX) TAE electrophoresis buffer was then added to the reservoir until the buffer just covered the agarose gel. $0.5 \mu \mathrm{l}$ of gel tracking dye (bromophenol blue) was added to $20 \mu \mathrm{l}$ of each sample with gentle mixing. $20 \mu 1$ of the sample was then loaded onto the wells of the gel, the mini horizontal electrophoresis gel set-up was then covered and the electrodes connected. Electrophoresis was carried out at $100-120 \mathrm{~mA}$ for $1 \mathrm{~h}$. At the completion of the electrophoresis, the gel was removed from the buffer and gel was viewed under a long wave UV-light box. The band pattern of the DNA fragments were then photographed with a Polaroid camera and documented using an electrophoresis gel documentation system. The molecular sizes of each plasmid were determined by comparison with plasmids of known mass (Datta et al., 1971).

\subsubsection{Plasmid curing}

Three of the MAR isolates, E. coli, Pseudomonas aeruginosa and Staphylococcus aureus were selected for the curing of antibiotic resistance plasmids. The plasmids were cured by treatment with acridine orange according to the method of Brown (2000). Buffered Peptone broth was prepared and supplemented with $0.1 \mathrm{mg} / \mathrm{ml}$ acridine orange. $20 \mu 1$ of overnight culture of the bacteria was sub cultured into $5 \mathrm{mls}$ of the nutrient broth containing acridine orange. The samples were then incubated at $37^{\circ} \mathrm{C}$ for 72 hours. After 72 hours of incubation, the isolates were swabbed to the Mueller Hinton agar plates and plasmid extraction was repeated on some of the organisms to verify if the plasmid were successfully cured.

\subsection{Physicochemical analysis}

The Water samples were immediately brought into Laboratory for the Estimation of various physicochemical parameters. Temperature $\left({ }^{\circ} \mathrm{C}\right)$ and $\mathrm{pH}$, turbidity (JTU), electrical conductivity $(\mu \mathrm{mho} / \mathrm{cm})$ were recorded at the time of sample collection by using Thermometer and Pocket Digital pH Meter. While other Parameters Such as DO, Hardness, Alkalinity, Chlorides, Phosphate, Nitrate, magnesium $(\mathrm{mg} / \mathrm{l})$, and sulphate $(\mathrm{mg} / \mathrm{l})$ were estimated in the Laboratory by using Indian Standard Procedures (Titration method, Atomic Absorption Spectrophotometer (AAS) Thermo M5 Model) (Trivedy and Goel,1986; APHA, 1985).

\section{Results}

The total bacterial, total coliform and total enteric bacteria counts of the water samples from six different local governments are depicted in Table 1. The mean TBC value ranges from $2.08 \times 10^{5}$ $\mathrm{CFU} / \mathrm{ml}$ to $6.0 \times 10^{6} \mathrm{CFU} / \mathrm{ml}$; the mean $\mathrm{TCC}$ value ranges from $2.41 \times 10^{5} \mathrm{CFU} / \mathrm{ml}$ to $3.75 \times 10^{6} \mathrm{CFU} / \mathrm{ml}$ while the mean TEC value ranges from $1.53 \times 10^{5} \mathrm{CFU} / \mathrm{ml}$ to $3.45 \times 10^{5} \mathrm{CFU} / \mathrm{ml}$.

The percentages distribution of isolated bacteria revealed Escherichia coli with the highest percentage (35\%), followed by Staphylococcus aureus (6.6\%), Enterococcus feacalis (8.6\%), Klebsiella spp (28.9\%), Enterobacter aerogenes (7.23\%), Pseudomonas aerogenes $(1.97 \%)$, Proteus vulgaris $(2.63 \%)$, Bacillus cereus (7.9\%) and Serratia marcenscens $(0.7 \%)$ with the least percentage distributions (Table 2).

All sixty nine (100\%) Gram positive bacteria isolated from water samples were highly resistant to ceftazidime and $13 \%$ were resistant to ofloxacin (Table 3). Meanwhile, $88 \%$ of eighty three (83) Gram negative bacteria isolated from the water samples were highly resistant to cefuroxime and $17 \%$ were resistant to gentamicin (Table 4).

Multiple antibiotics resistance (MAR) is higher among Gram negative isolates than Gram positive isolates (Table 5). Eighteen (18) out of thirty four (34) isolates selected, possessed single plasmid except E.coli29 which had 2 plasmids while the remaining 15 isolate had no plasmid with molecular weight ranging from 
$5.64 \mathrm{Kbp}$ to $23.13 \mathrm{Kbp}$. The plasmid pictorial representation of the and figure 2 respectively.

Gram positive and Gram negative isolates is depicted in figure 1

Table 1: Microbial Estimation (CFU/Ml) of Water Samples

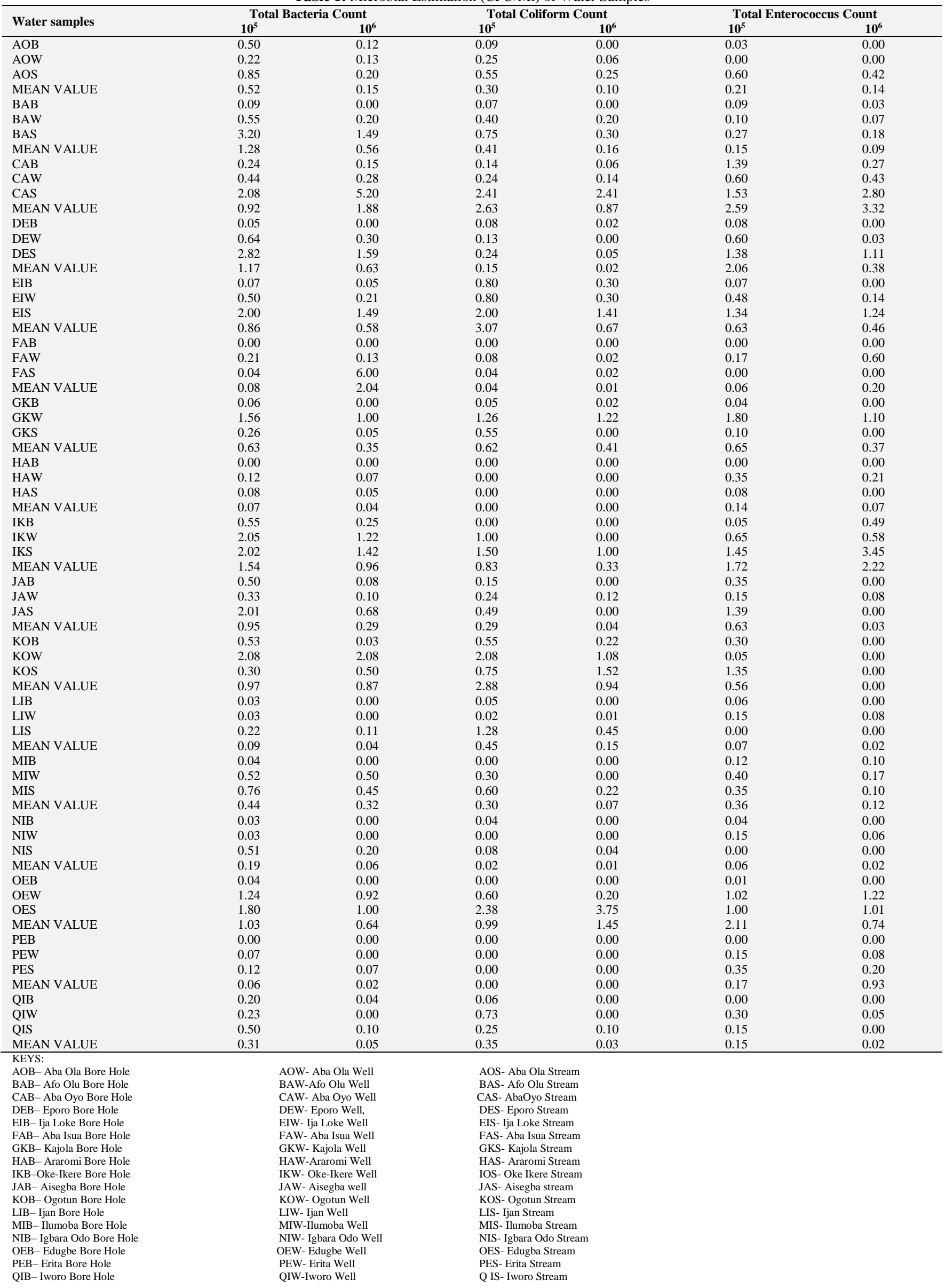


Table 2: Distribution of Organisms Isolated from Different Sampling Points

\begin{tabular}{|c|c|c|c|c|c|c|c|c|c|c|c|c|c|c|c|c|c|c|c|}
\hline \multirow{2}{*}{ Isolates } & \multicolumn{17}{|c|}{ Distribution } & \multirow{2}{*}{ Number of isolate } & \multirow{2}{*}{ Frequency $\%$} \\
\hline & A & B & $\mathrm{C}$ & $\mathrm{D}$ & $\mathrm{E}$ & $\mathrm{F}$ & $\mathrm{G}$ & $\mathrm{H}$ & I & $\mathrm{J}$ & $\mathrm{K}$ & $\mathrm{L}$ & M & $\mathrm{N}$ & $\mathrm{O}$ & $\mathrm{P}$ & Q & & \\
\hline Escherichia coli & 4 & 3 & 4 & 3 & 1 & 3 & 2 & 2 & 4 & 2 & 7 & 10 & 7 & 10 & 3 & 6 & 2 & 54 & 35.5 \\
\hline Staphylococcus aureus & 2 & - & - & - & 4 & - & - & - & 2 & - & 2 & - & 1 & - & 1 & - & 1 & 13 & 8.6 \\
\hline Enterococcus faecalis & 3 & 5 & - & 2 & 1 & 2 & 4 & 2 & - & 2 & 4 & 1 & - & 7 & - & 6 & 5 & 44 & 28.9 \\
\hline Enterobacter aerogenes & 1 & - & - & 4 & - & 2 & - & 2 & - & - & 1 & - & - & 1 & - & - & - & 10 & 6.6 \\
\hline Klebsiella spp & - & - & - & 2 & - & - & 1 & - & 2 & - & - & 3 & - & - & 1 & 1 & - & 11 & 7.2 \\
\hline Pseudomonas aeruginosa & 1 & - & - & - & - & - & 2 & - & - & - & - & - & - & - & - & - & - & 3 & 2.0 \\
\hline Proteus vulgaris & 2 & - & - & - & 1 & - & - & 1 & - & - & - & - & - & - & - & - & - & 4 & 2.6 \\
\hline Serratia marcescens & - & 1 & - & - & - & - & - & - & - & - & - & - & - & - & - & - & - & 1 & 0.7 \\
\hline Total & & & & & & & & & & & & & & & & & & 152 & 100 \\
\hline
\end{tabular}

Table 3: Antibiotics Resistance Pattern of Isolated Gram Negative Bacteria

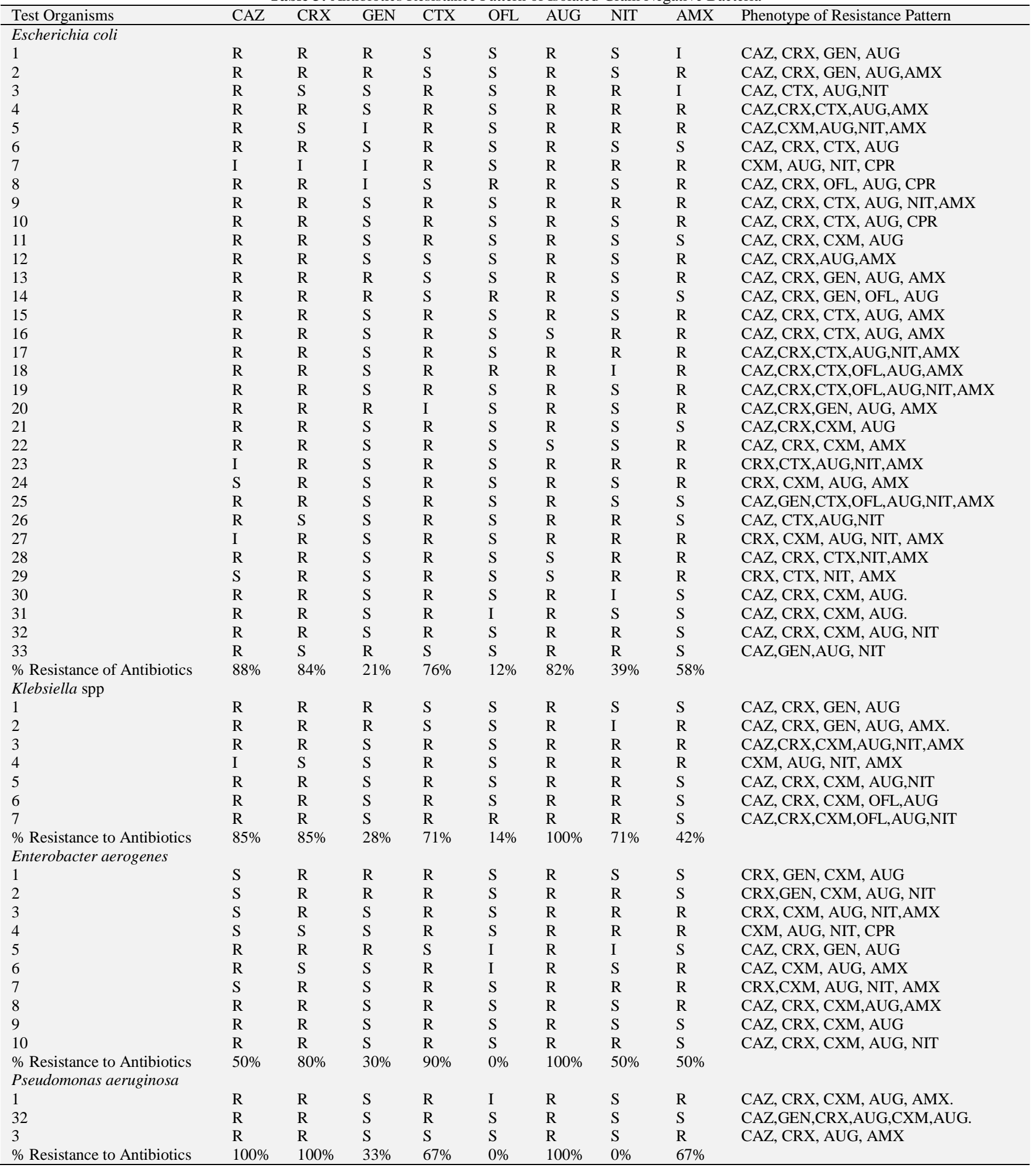




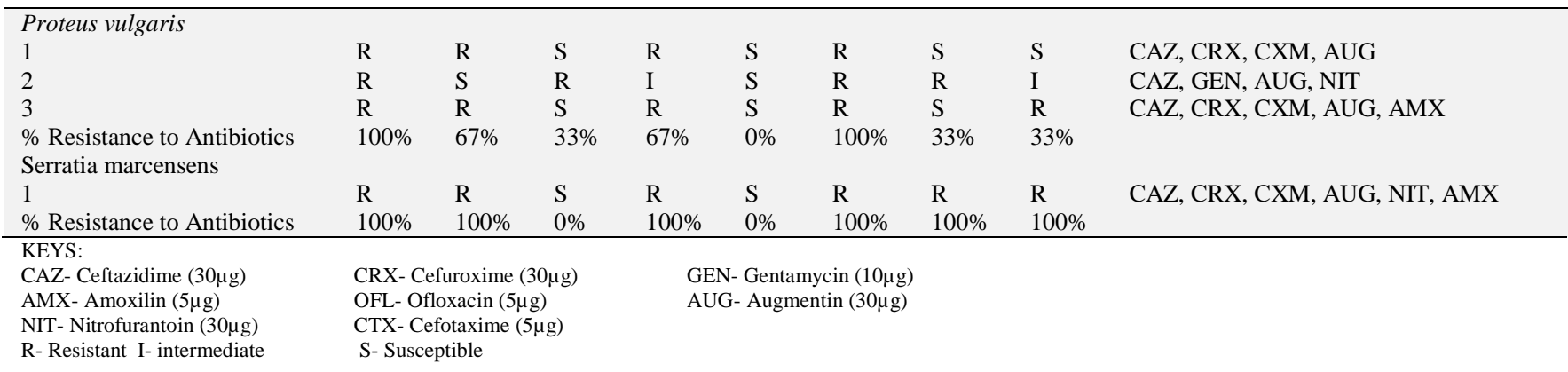

Table 4: Antibiotics Resistance Pattern of Gram Positive Bacteria from Water Samples

\begin{tabular}{|c|c|c|c|c|c|c|c|c|c|}
\hline Test Organism & CAZ & CTR & GEN & $\mathrm{CXC}$ & OFL & CRX & ERY & AUG & Phenotype of Resistance Pattern \\
\hline \multicolumn{10}{|l|}{ Staphylococcus aureus } \\
\hline 1 & $\mathrm{R}$ & $\mathrm{R}$ & $\mathrm{S}$ & $\mathrm{R}$ & $\mathrm{S}$ & $\mathrm{R}$ & $\mathrm{R}$ & $\mathrm{R}$ & CAZ,CTX,CXC,CRX,ERY,AUG. \\
\hline 2 & $\mathrm{R}$ & $\mathrm{R}$ & $\mathrm{R}$ & $\mathrm{R}$ & $\mathrm{S}$ & $\mathrm{R}$ & $\mathrm{R}$ & $\mathrm{R}$ & CAZ, GEN, CXC, ERY, AUG. \\
\hline 3 & $\mathrm{R}$ & $\mathrm{S}$ & $\mathrm{S}$ & $\mathrm{R}$ & $\mathrm{S}$ & $\mathrm{S}$ & $\mathrm{R}$ & $\mathrm{R}$ & CAZ, CXC, OXA, AUG. \\
\hline 4 & $\mathrm{R}$ & $\mathrm{S}$ & $\mathrm{R}$ & $\mathrm{R}$ & $\mathrm{S}$ & $\mathrm{S}$ & $\mathrm{R}$ & $\mathrm{R}$ & CAZ, GEN, CXC, ERY, AUG. \\
\hline 5 & $\mathrm{R}$ & $\mathrm{S}$ & $\mathrm{S}$ & $\mathrm{R}$ & $\mathrm{S}$ & $\mathrm{R}$ & $\mathrm{I}$ & $\mathrm{R}$ & $\mathrm{CAZ}, \mathrm{CXC}, \mathrm{CRX}, \mathrm{AUG}$ \\
\hline 6 & $\mathrm{R}$ & $\mathrm{S}$ & $\mathrm{R}$ & $\mathrm{S}$ & $\mathrm{S}$ & $\mathrm{R}$ & $\mathrm{S}$ & $\mathrm{R}$ & CAZ,GEN ,CRX, AUG. \\
\hline 7 & $\mathrm{R}$ & $\mathrm{S}$ & $\mathrm{S}$ & $\mathrm{R}$ & $\mathrm{S}$ & $\mathrm{S}$ & $\mathrm{R}$ & $\mathrm{R}$ & CAZ, CXC. ERY ,AUG. \\
\hline 8 & $\mathrm{R}$ & $\mathrm{S}$ & $\mathrm{R}$ & $\mathrm{R}$ & $\mathrm{S}$ & $\mathrm{R}$ & $\mathrm{R}$ & $\mathrm{R}$ & CAZ,GEN,CXC,CRX,ERY, AUG. \\
\hline 9 & $\mathrm{R}$ & $\mathrm{S}$ & I & $\mathrm{R}$ & $\mathrm{S}$ & $\mathrm{R}$ & $\mathrm{S}$ & $\mathrm{R}$ & CAZ, CXC ,CRX,AUG. \\
\hline 10 & $\mathrm{R}$ & $\mathrm{S}$ & $\mathrm{S}$ & $\mathrm{R}$ & $\mathrm{S}$ & $\mathrm{S}$ & $\mathrm{R}$ & $\mathrm{R}$ & CAZ,CXC,ERY ,AUG. \\
\hline$\%$ Resistance to Antibiotics & $100 \%$ & $10 \%$ & $40 \%$ & $90 \%$ & $0 \%$ & $50 \%$ & $70 \%$ & $100 \%$ & \\
\hline \multicolumn{10}{|l|}{ Klebsiella spp } \\
\hline 1 & $\mathrm{R}$ & $\mathrm{R}$ & $S$ & $\mathrm{~S}$ & $\mathrm{~S}$ & $\mathrm{~S}$ & $\mathrm{R}$ & $\mathrm{R}$ & CAZ, CTX, ERY, AUG. \\
\hline 2 & $\mathrm{R}$ & $\mathrm{S}$ & $\mathrm{S}$ & $\mathrm{R}$ & $\mathrm{S}$ & $\mathrm{R}$ & $\mathrm{R}$ & $\mathrm{R}$ & CAZ, CXC, CRX, ERY, AUG. \\
\hline 3 & $\mathrm{R}$ & $\mathrm{S}$ & $\mathrm{S}$ & $\mathrm{R}$ & $\mathrm{S}$ & $\mathrm{S}$ & $\mathrm{R}$ & $\mathrm{R}$ & CAZ, CXC, OXA, AUG. \\
\hline 5 & I & $\mathrm{S}$ & $\mathrm{R}$ & I & $\mathrm{S}$ & $\mathrm{R}$ & $\mathrm{R}$ & $\mathrm{R}$ & GEN ,CRX, OXA, AUG. \\
\hline 6 & $\mathrm{R}$ & $\mathrm{S}$ & $\mathrm{S}$ & $\mathrm{R}$ & $\mathrm{S}$ & $\mathrm{R}$ & $\mathrm{R}$ & $\mathrm{R}$ & CAZ,CXC,CRX,ERY, AUG. \\
\hline 7 & $\mathrm{R}$ & $\mathrm{S}$ & S & $\mathrm{R}$ & $\mathrm{S}$ & $\mathrm{R}$ & I & $\mathrm{R}$ & CAZ, CXC. CRX ,AUG. \\
\hline 8 & $\mathrm{R}$ & $\mathrm{S}$ & $\mathrm{S}$ & $\mathrm{R}$ & $\mathrm{S}$ & $\mathrm{S}$ & $\mathrm{R}$ & $\mathrm{R}$ & CAX, CXC, OXA, AUG. \\
\hline$\%$ Resistance to Antibiotics & $88 \%$ & $25 \%$ & $12 \%$ & $75 \%$ & $0 \%$ & $63 \%$ & $87 \%$ & $100 \%$ & \\
\hline \multicolumn{10}{|l|}{ Enterococcus faecalis } \\
\hline 1 & $\mathrm{R}$ & $\mathrm{S}$ & $\mathrm{R}$ & $\mathrm{R}$ & $\mathrm{S}$ & $\mathrm{S}$ & $\mathrm{R}$ & $\mathrm{R}$ & CAZ,GEN,CXC,ERY,AUG. \\
\hline 2 & $\mathrm{R}$ & $\mathrm{R}$ & $\mathrm{S}$ & $\mathrm{R}$ & $\mathrm{S}$ & $\mathrm{R}$ & $\mathrm{R}$ & $\mathrm{R}$ & CAZ,CTX,GEN,CXC,CRX,ERY,AUG. \\
\hline 3 & $\mathrm{R}$ & $\mathrm{S}$ & $\mathrm{S}$ & $\mathrm{S}$ & $\mathrm{R}$ & $\mathrm{S}$ & $\mathrm{R}$ & $\mathrm{R}$ & CAZ, OFL, ERY, AUG. \\
\hline 4 & $\mathrm{~S}$ & $\mathrm{~S}$ & $\mathrm{~S}$ & $\mathrm{R}$ & $\mathrm{S}$ & $\mathrm{R}$ & $\mathrm{R}$ & $\mathrm{R}$ & COX, CRX, ERY, AUG. \\
\hline 5 & $\mathrm{R}$ & $\mathrm{R}$ & $\mathrm{S}$ & I & $\mathrm{S}$ & $\mathrm{S}$ & $\mathrm{R}$ & $\mathrm{R}$ & CAZ,CTX,ERY,AUG. \\
\hline 6 & $\mathrm{R}$ & $\mathrm{S}$ & $\mathrm{S}$ & $\mathrm{R}$ & $\mathrm{S}$ & $\mathrm{S}$ & $\mathrm{R}$ & $\mathrm{R}$ & CAZ ,CXC ,ERY, AUG. \\
\hline 7 & $\mathrm{R}$ & $\mathrm{S}$ & $\mathrm{S}$ & $\mathrm{R}$ & $\mathrm{S}$ & $\mathrm{R}$ & $\mathrm{R}$ & $\mathrm{R}$ & CAZ, CXC. ERY ,AUG. \\
\hline 8 & $\mathrm{R}$ & $\mathrm{S}$ & $\mathrm{S}$ & $\mathrm{R}$ & $\mathrm{S}$ & $\mathrm{S}$ & $\mathrm{R}$ & $\mathrm{R}$ & CAX, CXC, ERY, AUG. \\
\hline 9 & $\mathrm{~S}$ & $\mathrm{~S}$ & $S$ & $\mathrm{R}$ & $\mathrm{S}$ & $\mathrm{R}$ & $\mathrm{R}$ & $\mathrm{R}$ & COX ,CRX, ERY, AUG. \\
\hline 10 & $\mathrm{R}$ & $\mathrm{S}$ & $\mathrm{S}$ & $\mathrm{R}$ & $\mathrm{S}$ & $\mathrm{R}$ & $\mathrm{R}$ & $\mathrm{R}$ & CAZ,CXC,CRX,ERY,AUG. \\
\hline 11 & $\mathrm{~S}$ & $\mathrm{~S}$ & $\mathrm{~S}$ & $\mathrm{R}$ & $\mathrm{S}$ & $\mathrm{R}$ & $\mathrm{R}$ & $\mathrm{R}$ & COX, CRX, ERY, AUG. \\
\hline 14 & $\mathrm{R}$ & $\mathrm{S}$ & $\mathrm{S}$ & $\mathrm{R}$ & $\mathrm{S}$ & $\mathrm{S}$ & $\mathrm{R}$ & $\mathrm{R}$ & CAZ,CXC, ERY, AUG. \\
\hline 15 & $\mathrm{R}$ & $\mathrm{R}$ & $\mathrm{S}$ & $\mathrm{R}$ & $\mathrm{S}$ & $\mathrm{R}$ & I & $\mathrm{R}$ & CAZ,CTX,CXC,CRX,AUG. \\
\hline 16 & I & $\mathrm{R}$ & $S$ & $\mathrm{R}$ & $\mathrm{R}$ & $\mathrm{R}$ & $\mathrm{S}$ & I & CTX, GEN, OFL, CRX. \\
\hline 17 & $\mathrm{R}$ & $\mathrm{R}$ & $\mathrm{S}$ & $\mathrm{R}$ & $\mathrm{S}$ & $\mathrm{R}$ & $\mathrm{R}$ & $\mathrm{R}$ & CAZ,CTX,CXC,CRX,ERY, AUG. \\
\hline 18 & $\mathrm{~S}$ & $\mathrm{~S}$ & $\mathrm{R}$ & $\mathrm{S}$ & $\mathrm{R}$ & $\mathrm{R}$ & $\mathrm{S}$ & $\mathrm{R}$ & GEN ,OFL, CRX,AUG. \\
\hline 19 & $\mathrm{R}$ & $\mathrm{R}$ & $\mathrm{S}$ & $\mathrm{R}$ & $\mathrm{S}$ & $\mathrm{R}$ & $\mathrm{S}$ & $\mathrm{R}$ & CAZ,CTX,CXC,CRX, AUG. \\
\hline 20 & $\mathrm{R}$ & $\mathrm{R}$ & $\mathrm{R}$ & $\mathrm{R}$ & $\mathrm{S}$ & $\mathrm{S}$ & $\mathrm{S}$ & $\mathrm{R}$ & CAZ,CTX, GEN,COX,AUG \\
\hline 21 & $\mathrm{R}$ & $\mathrm{S}$ & $\mathrm{R}$ & $\mathrm{R}$ & $\mathrm{S}$ & $\mathrm{R}$ & $\mathrm{S}$ & $\mathrm{R}$ & CAZ,GEN,CXC,CRX AUG. \\
\hline 22 & $\mathrm{R}$ & $\mathrm{S}$ & $S$ & $\mathrm{R}$ & $\mathrm{R}$ & $\mathrm{R}$ & $\mathrm{S}$ & $\mathrm{R}$ & CAZ,CXC, OFL,CRX AUG. \\
\hline 23 & $\mathrm{R}$ & $\mathrm{S}$ & $\mathrm{S}$ & $\mathrm{R}$ & $\mathrm{S}$ & $\mathrm{R}$ & $\mathrm{S}$ & $\mathrm{R}$ & CAZ, CXC, CRX, AUG. \\
\hline 24 & $\mathrm{R}$ & $S$ & $S$ & $\mathrm{~S}$ & $\mathrm{~S}$ & $\mathrm{R}$ & $\mathrm{R}$ & $\mathrm{R}$ & CAZ, CRX, ERY, AUG. \\
\hline 25 & $\mathrm{~S}$ & $\mathrm{R}$ & $S$ & $\mathrm{~S}$ & $\mathrm{~S}$ & $\mathrm{R}$ & $\mathrm{R}$ & $\mathrm{R}$ & CTX, CRX, OXA, AUG. \\
\hline 26 & $\mathrm{R}$ & $\mathrm{S}$ & $\mathrm{S}$ & $\mathrm{R}$ & $\mathrm{S}$ & $\mathrm{R}$ & $\mathrm{R}$ & $\mathrm{R}$ & CAZ,CXC,CRX,ERY,AUG. \\
\hline 27 & $\mathrm{~S}$ & $\mathrm{R}$ & $S$ & $\mathrm{R}$ & $\mathrm{R}$ & $\mathrm{S}$ & $\mathrm{R}$ & $\mathrm{R}$ & CTX,COX,OFL,ERY,AUG. \\
\hline 28 & I & $\mathrm{R}$ & $\mathrm{S}$ & $\mathrm{R}$ & $\mathrm{S}$ & $\mathrm{R}$ & $\mathrm{R}$ & $\mathrm{R}$ & CTX,CXC,CRX,ERY,AUG. \\
\hline 29 & $\mathrm{~S}$ & $\mathrm{R}$ & $S$ & $\mathrm{R}$ & $\mathrm{S}$ & $\mathrm{R}$ & $\mathrm{S}$ & $\mathrm{R}$ & CTX, CXC, CRX, AUG. \\
\hline 30 & $\mathrm{R}$ & $\mathrm{R}$ & $\mathrm{S}$ & $\mathrm{R}$ & $\mathrm{S}$ & $\mathrm{R}$ & $\mathrm{R}$ & $\mathrm{R}$ & CAZ,CTX,COX,CRX, ERY,AUG. \\
\hline$\%$ Resistance to antibiotics & $73 \%$ & $46 \%$ & $16 \%$ & $73 \%$ & $13 \%$ & $85 \%$ & $66 \%$ & $100 \%$ & \\
\hline \multicolumn{10}{|l|}{ KEYS: } \\
\hline CAZ - Ceftazidime & & GEN & jentamic & & & & $\mathrm{CXC}-\mathrm{C}$ & otazine & \\
\hline ERY - Erythromycin & & AUG & ugmenti & & & & OFL - O & xacin & \\
\hline CRX -Cefuroxime & & CTX & ftaxidin & & & & & & \\
\hline
\end{tabular}


Table 5: Phenotypic Pattern of Multiple Antibiotic Resistance (MAR) Bacteria

\begin{tabular}{|c|c|c|c|c|}
\hline No of Isolates & Antibiotics & $\begin{array}{l}\text { Number of Occu } \\
\text { Gram negative } \\
n=83(\%)\end{array}$ & $\begin{array}{l}\text { Gram positive } \\
\mathrm{n}=69(\%)\end{array}$ & $\begin{array}{l}\text { Total Isolates } \\
(\mathrm{n}=152)\end{array}$ \\
\hline \multirow{10}{*}{4} & CAZ,CTX,CRX,AUG. & & $10(14.49 \%)$ & $10(6.58 \%)$ \\
\hline & CAZ,CTX,OXA,AUG & 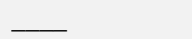 & $3(4.35 \%)$ & $3(1.97 \%)$ \\
\hline & CAZ,CRX,OXA,AUG & 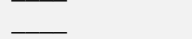 & $4(5.80 \%)$ & $4(2.63 \%)$ \\
\hline & CAZ,COX,OXA,AUG & 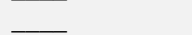 & $4(5.80 \%)$ & $4(2.63 \%)$ \\
\hline & CAZ,COX,OXA,AUG & & $4(5.80 \%)$ & $4(2.63 \%)$ \\
\hline & CAZ,CRX,GEN,AUG & $\overline{2(2.4} 1 \%)$ & $\underline{-}$ & $2(1.32 \%)$ \\
\hline & CAZ,CRX,CXM,AUG & $5(6.02 \%)$ & $\overline{1}$ & $5(3.29 \%)$ \\
\hline & CAZ,CXM,NIT,AUG & $3(3.61 \%)$ & 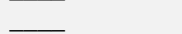 & $3(0.02 \%)$ \\
\hline & CXM,AUG,NIT,AMX & $2(2.41 \%)$ & & $2(1.32 \%)$ \\
\hline & CAZ,OFL,AUG,NIT & $10(12.04)$ & & $10(7.92 \%)$ \\
\hline \multirow{8}{*}{5} & CAZ,COX,CRX,OXA,AUG & ( & $\overline{5(7.24 \%)}$ & $5(3.29 \%)$ \\
\hline & CAZ,COX,CRX,OXA,AUG & 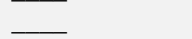 & $2(2.89 \%)$ & $2(1.32 \%)$ \\
\hline & CAZ,CTX,CRX,OXA,AUG & & $2(2.89 \%)$ & $2(1.32 \%)$ \\
\hline & CAZ,CRX,CXM,AUG,CPR & $\overline{2(2.4} 1 \%)$ & $\underline{-}$ & $2(1.32 \%)$ \\
\hline & CAZ,CRX,CXM,AUG,CPR & $6(7.235)$ & $\overline{\mathrm{C}}$ & $6(3.95 \%)$ \\
\hline & CAZ,CRX,NIT,AUG,CPR & $9(10.84 \%)$ & & $9(5.92 \%)$ \\
\hline & CAZ,CRX,CXM,AUG,NIT & $9(10.84 \%)$ & & $9(5.92 \%)$ \\
\hline & CAZ, CRX, AUG, NIT, CPR. & $9(10.84 \%)$ & & $9(5.92 \%)$ \\
\hline \multirow{7}{*}{6} & CAZ,CTX,COX,CRX,OXA, AUG. & + & $\overline{4(5.8} \%)$ & $4(2.63 \%)$ \\
\hline & CAZ,CTX,CRX,COX, OXA,AUG & & $12(17.39 \%)$ & $12(7.89 \%)$ \\
\hline & CAZ,CRX,CXM,AUG,NIT, CPR, & $\overline{9(10.84 \%)}$ & 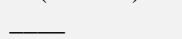 & $9(5.92 \%)$ \\
\hline & CAZ,CRX,OFL,AUG,NIT,CPR & $3(12.05 \%)$ & $\overline{-}$ & $3(6.58 \%)$ \\
\hline & CAZ,CRX,GEN,CXM,AUG,NIT & $6(7.23 \%)$ & & $6(3.95 \%)$ \\
\hline & CAZ,CRX.GEN,OFL,AUG,CPR & $2(2.41 \%)$ & $\overline{-}$ & $2(1.32 \%)$ \\
\hline & CAZ,CXM,OFL,AUG,NIT,CPR & $1(1.20 \%)$ & & $1(0.66 \%)$ \\
\hline \multirow{3}{*}{7} & CAZ,CTX,GEN,COX,CRX,OXA,AUG & - & $\overline{3(4.35 \%)}$ & $3(1.97 \%)$ \\
\hline & CAZ,CTX,COX,OFL,CRX,OXA,AUG & $\overline{-}$ & $4(5.80 \%)$ & $4(2.63 \%)$ \\
\hline & CAZ, CTX, CRX, GEN, AUG, NIT, AMX. & $\overline{2(2.4} 1 \%)$ & & $2(1.32 \%)$ \\
\hline
\end{tabular}

KEYS:

CAZ $=$ Ceftazidine $\quad$ GEN $=$ Gentamycin $\quad$ COX $=$ Cloxacillin

AUG $=$ Augmentin $\quad$ OFL $=$ Ofloxacin $\quad$ CRX $=$ Ceftaxidine

NIT $=$ Nitrofurantoin $\quad$ CXM $=$ Cefixime $\quad$ AMX $=$ Ciprofloxacin

$\mathrm{n}=$ number of each of the isolates

Table 6: Plasmid Profile of Selected Multiple Antibiotics Resistance (MAR) Bacterial Isolated from Water

\begin{tabular}{|c|c|c|}
\hline Isolates & Number of Plasmids (Kbp) n-34 & Molecular weight of Plasmid \\
\hline Escherichia coli 4 & 1 & 23.130 \\
\hline Escherichia coli 34 & 1 & 23.130 \\
\hline Pseudomonas aeruiginosa 49 & - & 23.130 \\
\hline Staphylococcus aureus 42 & 1 & - \\
\hline Pseudomonas aeruginosa 22 & 1 & 23.130 \\
\hline Staphylococcus aureus 2 & 1 & 23.130 \\
\hline Klebsiella sp 13 & - & 23.130 \\
\hline Bacillus cereus 43 & - & - \\
\hline Pseudomonas aeruginosa 5 & - & - \\
\hline Bacillus cereus 8 & - & - \\
\hline Enterobacter aerogenes 14 & - & - \\
\hline Klebsiela sp 18 & - & - \\
\hline Serratia marcenscens 21 & - & - \\
\hline Escherichia coli 25 & 1 & 9.414 \\
\hline Staphylococcus aureus 27 & - & - \\
\hline Escherichia coli 29 & 2 & $23.130-5.64$ \\
\hline Bacillus cereus 38 & - & - \\
\hline Enterococcus faecalis 40 & - & - \\
\hline Enterobacter aerogenes 41 & 1 & 5.640 \\
\hline Enterococcus faecalis 45 & 1 & 23.130 \\
\hline Enterococcus faecalis 47 & - & - \\
\hline Enterobacter aerogenes 48 & - & - \\
\hline Proteus vulgaris 54 & 1 & 23.130 \\
\hline Bacillus cereus 56 & - & - \\
\hline Escherichia coli 59 & 1 & 23.130 \\
\hline Staphylococcus aureus 60 & - & - \\
\hline Enterobacter aerogenes 61 & 1 & 23.130 \\
\hline Proteus vulgaris 62 & 1 & - \\
\hline Staphylococcus aureus 10 & 1 & 23.130 \\
\hline Proteus vulgaris 35 & 1 & 5.640 \\
\hline Pseudomonas aeruginosa 32 & 1 & 9.416 \\
\hline Bacillus cereus 1 & 1 & 23.130 \\
\hline$\%$ Carrier of Plasmid & $56 \%$ & \\
\hline
\end{tabular}




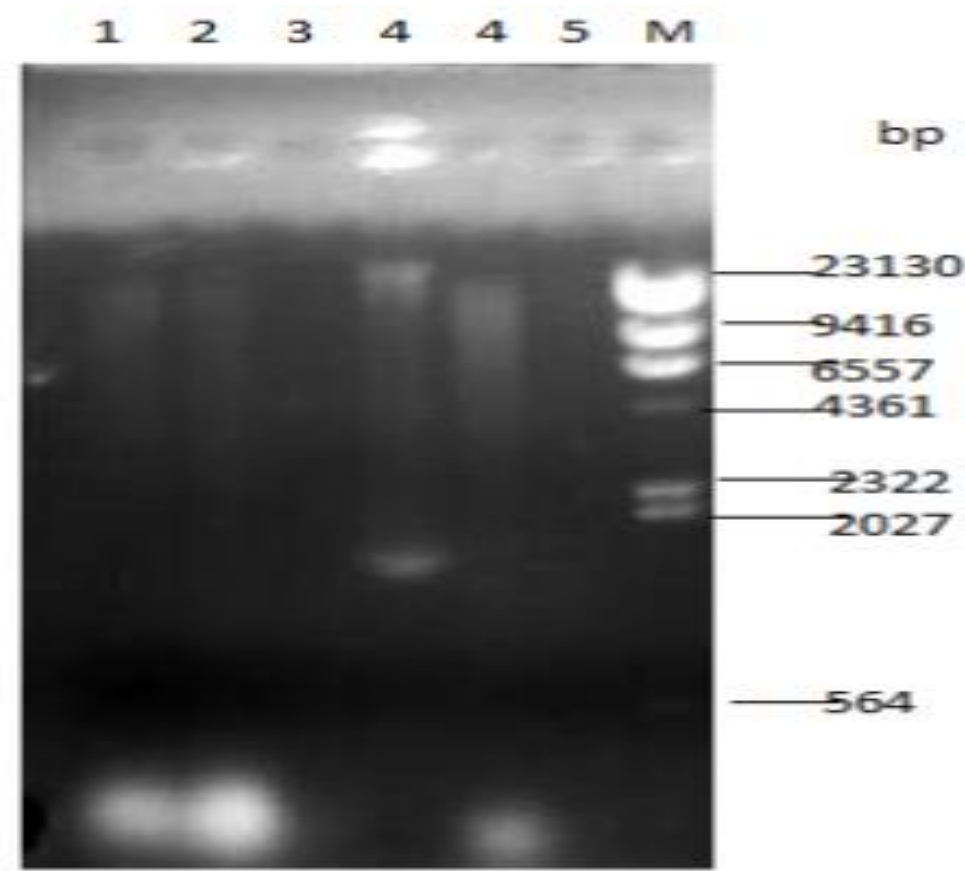

Fig 1: Plasmid Profile for Gram Positive Multiple Antibiotics Resistant Isolates.

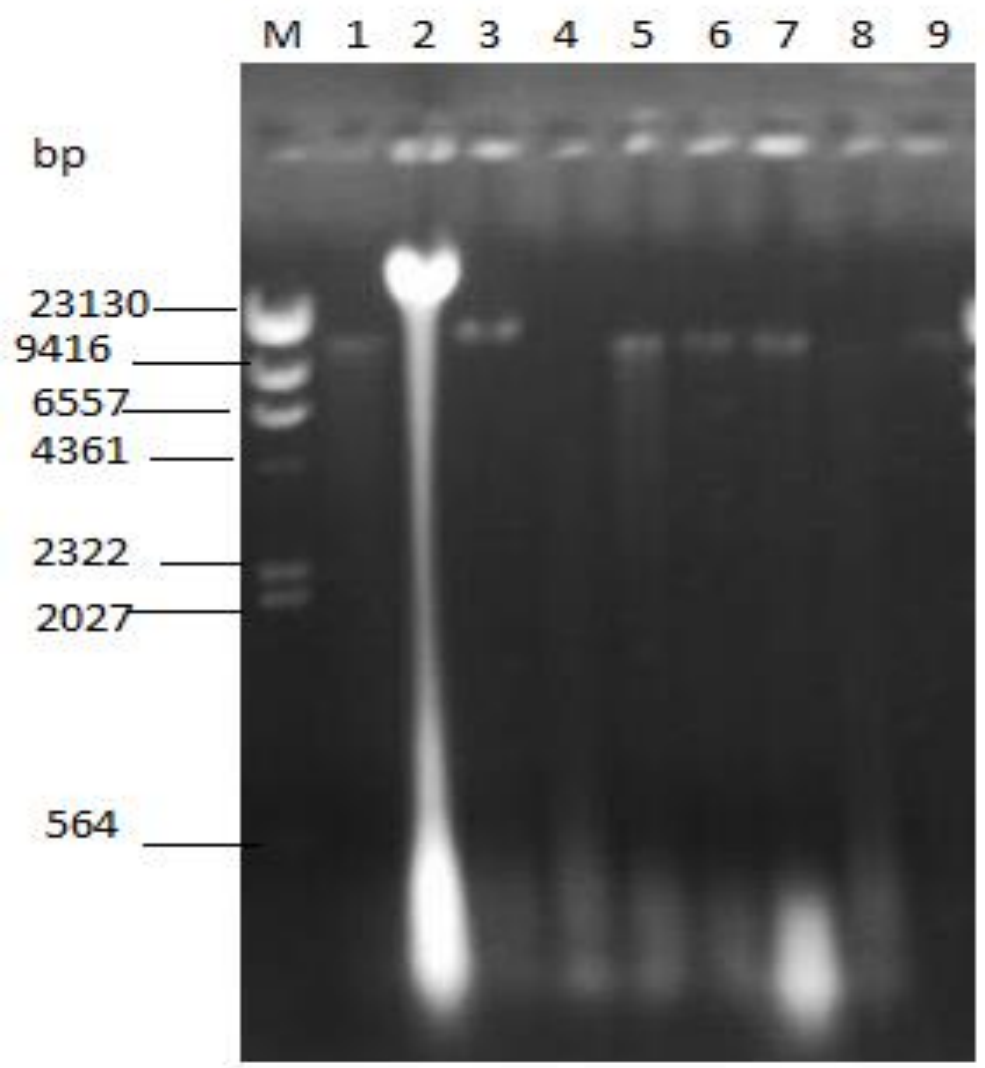

Fig. 2: Plasmid Profile for Gram Negative Multiple Antibiotics Resistant Isolates.

It was confirmed that Pseudomonas aeruginosa became susceptible to augmentin after been cured and Staphylococcus aureus also became susceptible to ceftriazole after curing while $E$. coli still maintained the earlier resistant pattern (Tables 7 and 8). Table 9 revealed the plasmid profiles of the multiple antibiotics resistant (MAR) bacteria selected for plasmid curing. This indicated the lost of plasmids in the three bacterial isolates after subjection to curing as depicted in figure 3.

The physiochemical results of the water samples ranged as follows: pH (6.5 - 6.80), colour (colourless), odor (odourless), taste (eusipid), temperature $(25-27)^{\circ} \mathrm{C}$, turbidity $(0.010-0.028) \mathrm{NTU}$, total suspended solid $(0.75-1.06)$, conductivity $(0.000-0.030)$ mhos, dissolved oxygen $(12.180$ - 22.235) $\mathrm{mg} / \mathrm{L}$, biochemical oxygen demand $(0.610-12.150) \mathrm{mg} / \mathrm{L}$, acidity $(10.10-13.000)$ $\mathrm{mg} / \mathrm{L}$, alkalinity $(25.000-70.000) \mathrm{mg} / \mathrm{L}$, hardness $(22.30-$ $60.000) \mathrm{mg} / \mathrm{L}$. Nitrate $(0.000 \mathrm{mg} / \mathrm{L})$, Sulphate $(10.000-12.000)$ $\mathrm{mg} / \mathrm{L}$, Chloride (15.000 - 76.000) mg/L, Magnesium (55.000 79.00) $\mathrm{mg} / \mathrm{L}$ and Phosphate $(0.000 \mathrm{mg} / \mathrm{L})$. It was observed that chloride and magnesium were present in the samples. 
Table 7: Antibiotic Resistance Pattern of Selected Bacteria Isolate from Water Sample

\begin{tabular}{|c|c|c|c|c|c|c|c|c|c|c|c|c|}
\hline \multirow{2}{*}{ Isolates } & \multirow[b]{2}{*}{$\mathrm{CXC}$} & \multicolumn{9}{|c|}{ Antibiotics } & \multicolumn{2}{|r|}{ Phenotype of Resistance pattern } \\
\hline & & ERY & AUG & NIT & $\mathrm{CAZ}$ & CRX & GEN & CTX & OFL & AMX & CTR & \\
\hline Escherichia coli25 & ND & ND & $\mathrm{R}$ & $\mathrm{S}$ & $\mathrm{R}$ & $\mathrm{R}$ & $\mathrm{S}$ & $\mathrm{R}$ & $\mathrm{S}$ & $\mathrm{S}$ & ND & CAZ,CRX,CTX,AUG \\
\hline $\begin{array}{l}\text { Pseudomonas aeru- } \\
\text { ginosa } 32\end{array}$ & ND & ND & $\mathrm{R}$ & $\mathrm{S}$ & $\mathrm{R}$ & $\mathrm{R}$ & $\mathrm{S}$ & $\mathrm{R}$ & $\mathrm{S}$ & $\mathrm{S}$ & ND & CAZ,CRX,CTX,AUG \\
\hline $\begin{array}{l}\text { Staphylococcus aure- } \\
\text { us2 }\end{array}$ & $\mathrm{R}$ & $\mathrm{R}$ & $\mathrm{R}$ & ND & $\mathrm{R}$ & $\mathrm{R}$ & $\mathrm{R}$ & ND & $\mathrm{S}$ & ND & $\mathrm{R}$ & GEN,CRX,AUG,CXC,ERY,CTR,CAZ \\
\hline
\end{tabular}

KEYS:

CAZ - Ceftazidime

GEN - Gentamicin

CXC - Cefotazine

ERY - Erythromycin

AUG -Augmentin

OFL - Ofloxacin

CRX -Cefuroxime

CTX -Ceftaxidine

NIT - Nitrofurantoin

AMX - Amoxilin

CTR - Ceftriazole

I- Intermediate

R- Resistant

S- Susceptible

ND- Not determined

Table 8: Antibiotic Susceptibility Pattern of Selected Bacteria Isolated from Water Sample after Curing

\begin{tabular}{|c|c|c|c|c|c|c|c|c|c|c|c|c|}
\hline \multirow{2}{*}{ Isolates } & \multirow[b]{2}{*}{$\mathrm{CXC}$} & \multicolumn{10}{|c|}{ Antibiotics } & \multirow{2}{*}{ Phenotype of Resistance pattern } \\
\hline & & ERY & AUG & NIT & CAZ & CRX & GEN & CTX & OFL & AMX & CTR & \\
\hline Escherichia coli25 & ND & ND & $\mathrm{R}$ & $\mathrm{S}$ & $\mathrm{R}$ & $\mathrm{R}$ & $\mathrm{S}$ & $\mathrm{R}$ & $\mathrm{S}$ & $\mathrm{S}$ & ND & CAZ,CRX,CTX,AUG \\
\hline $\begin{array}{l}\text { Pseudomonas } \\
\text { aeruginosa32 }\end{array}$ & ND & ND & $\mathrm{S}$ & S & $\mathrm{R}$ & $\mathrm{R}$ & $\mathrm{S}$ & $\mathrm{R}$ & $S$ & S & ND & CAZ,CRX,CTX,AUG \\
\hline $\begin{array}{l}\text { Staphylococcus } \\
\text { aureus } 2\end{array}$ & $\mathrm{R}$ & $\mathrm{R}$ & $\mathrm{R}$ & ND & $\mathrm{R}$ & $\mathrm{R}$ & $\mathrm{R}$ & ND & S & ND & $\mathrm{R}$ & GEN,CRX,AUG,CXC,ERY,CTR,CAZ \\
\hline
\end{tabular}

CAZ - Ceftazidime

GEN - Gentamicin

CXC - Cefotazine

ERY - Erythromycin

AUG -Augmentin

OFL - Ofloxacin

CRX -Cefuroxime

CTX -Ceftaxidine

NIT - Nitrofurantoin

AMX - Amoxilin

CTR - Ceftriazole

I- Intermediate

R- Resistant

S- Susceptible

ND- Not determined

Table 9: Plasmid Profile of MAR Bacteria Isolated from Water Sample after Curing

\begin{tabular}{lll} 
& Table 9: Plasmid Profile of MAR Bacteria Isolated from Water Sample after Curing & Molecular weight of Plasmid \\
\hline Staphylococcus aureus2 & Number of Plasmids (Kbp) & - \\
Escherichia coli 25 & - & - \\
Pseudomonas auriginosa 32 & - & - \\
\hline
\end{tabular}

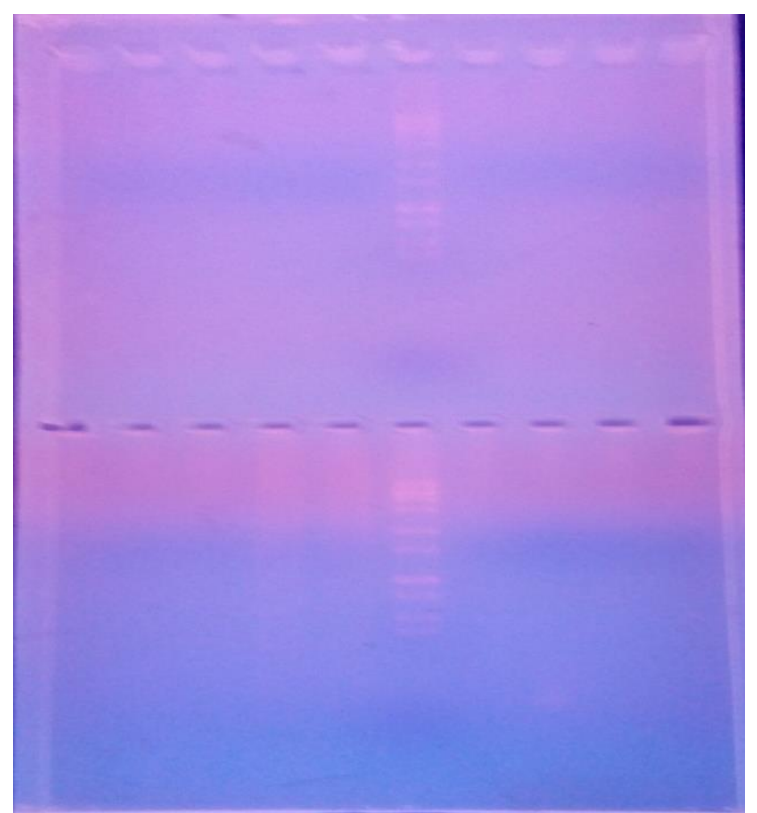

Fig. 3: Plasmid Profile for Multiple Antibiotics Resistant Isolates from Water Sources after Curing. 
Table 10: Physicochemical Properties of Water Sample

\begin{tabular}{|c|c|c|c|c|c|c|}
\hline \multirow{2}{*}{ PARAMETERS } & \multicolumn{4}{|c|}{ Results } & \multirow[b]{2}{*}{$\mathrm{E}$} & \multirow[b]{2}{*}{$\mathrm{F}$} \\
\hline & A & B & $\mathrm{C}$ & $\mathrm{D}$ & & \\
\hline Temperature $\left({ }^{\circ} \mathrm{C}\right)$ & 27.0 & 26.2 & 25.3 & 25.0 & 26.2 & 26.00 \\
\hline $\mathrm{pH}$ & 6.5 & 6.7 & 6.6 & 6.80 & 6.5 & 6.80 \\
\hline Conductivity (NH/CM) & 0.03 & 0.02 & 0.01 & 0.00 & 0.02 & 0.03 \\
\hline Turbidity (NTU) & 0.028 & 0.000 & 0.000 & 0.000 & 0.010 & 0.020 \\
\hline Dissolved oxygen & 22.235 & 15.180 & 16.100 & 15.180 & 18.000 & 12.180 \\
\hline Total hardness $(\mathrm{mg} / \mathrm{l})$ & 25.00 & 22.3 & 40.00 & 25.00 & 50.00 & 60.00 \\
\hline Total alkalinity & 35.00 & 25.00 & 27.00 & 35.00 & 25.00 & 70.00 \\
\hline Odour & Odourless & Odourless & Odourless & Odourless & Odourless & Odourless \\
\hline Nitrate $(\mathrm{mg} / \mathrm{l})$ & 0.00 & 0.00 & 0.00 & 0.00 & 0.00 & 0.00 \\
\hline Sulphate (mg/l) & 12.000 & 11.000 & 10.000 & 11.000 & 10.000 & 11.000 \\
\hline Chloride (mg/l) & 15.00 & 55.00 & 76.00 & 26.00 & 20.00 & 25.00 \\
\hline Phosphate (mg/l) & 0.00 & 0.00 & 0.00 & 0.00 & 0.00 & 0.00 \\
\hline Magnesium (mg/l) & 77.00 & 56.00 & 64.00 & 79.00 & 55.00 & 77.00 \\
\hline
\end{tabular}

KEYS: Aba Ola Bore Hole (Ekiti East Local Government Area)

$\begin{array}{ll}\text { A - } & \text { Aba Ola Bore Hole (Ekiti East Local Government Area) } \\ \text { B - } & \text { Eporo Bore Hole (Ekiti South West Local Government Area) }\end{array}$

C - Kajola Well (Emure Local Government Area)

D - $\quad$ Ogotun Bore Hole (Gbonyin Local Government Area)

E - $\quad$ Oke Ikere Well (Ikere Local Government Area)

F - Igbara Odo stream (Ise/Orun Local Government Area)

\section{Discussion}

Water is natural resources that are very essential to life and other living things. It is useful in various aspect of life such as: in cooking, agricultural practices and drinking. Ground water has a unique features compare to other sources of water which render them suitable for public supply (Alexandra, 2008). The quality of water is determined by bacteriological, physiochemical and mineral analysis (Makinde and Akande, 2012). The bacteriological analysis of the water samples showed the extent to which the water was contaminated by various microorganisms, most especially coliform bacteria which could be attributed to contamination with faeces of either human or animal origin or as a result of inadequately treated sewage discharge (WHO, 2006).

The mean of the total bacterial, total coliform and total enterococcal counts of the water samples in this present study were higher than the specified limit advocated by WHO standard (2006). This might be poor hygiene and sanitary conditions such as clothe and dishwashing as well as defecating in and near the water bodies, coupled with the location of the water considering the bushes and shrubs around the water bodies; which could serve as route for possible contaminations (Okonko et al., 2008). This is in accordance with the report of Edama et al. (2001) which explains that the presence of bushes and shrubs around water bodies makes it likely and possible of some individuals (man or animal) which may come around to drink water thereafter defecate in or around the surface water. Furthermore, microbial contamination of drinkable water such as underground water according to Roohul et al., (2012), may be attributed to leakage in pipes; cross contamination with wastewater; poorly constructed well head; short distance between water supply network and sewage supply; construction of septic tanks near wells and drinking water supply lines; run-offs infiltration of wastes and direct deposition of waste water through leakage. This evident the high microbial load encountered for the well and bore-hole water analyzed in present study.

Majority of the bacteria species that were isolated in this study were identified to be same as those commonly encountered in water and aquatic environments as reported by Nafaida et al., (2006) and Nicholas et al., (2009). They were detected to be members of coliforms, which are Gram negative, facultative anaerobes and non-spore formers that ferment lactose within 48 hours (Prescott et al., 2008). The high number of bacteria from the family of Enterobacteriaceae and coliform bacteria is an indication that the water samples are not portable and thus unfit for domestic use (WHO, 2006).

The isolation of Escherichia coli from the water samples correlates with the past studies that have presented Escherichia coli as a common encounter in different water sources such as rivers, streams, rain water, well water, underground water and even pipe borne water (EPA, 2002). The correlation of this study with previous study is making it seem like Escherichia coli is a normal flora of water bodies and can be isolated from any water body as earlier reported by Zamxaka et al. (2004). The implications of this organism in water and food related pathogenic infections have been reported by different researcher (Wastesan et al., 2001; Kaper et al., 2004).

All the bacteria isolated during this investigation have however been reported by Cheesbrough (2004) as potential pathogens. Following the report of Yagoub and Ahmed (2010), Pseudomonas auruginosa and other potentially pathogenic bacteria is significant enough to admit that the quality of these water sources has been adversely deteriorated thereby subjecting the immunecompromised individual in the community patients to greater health risks. Going by the description of Schlegel (2002), Enterobacter aerogenes isolated from these water samples are regarded as non-fecal coliforms mostly found in vegetation and soil; this further explains how the bushes and shrubs around the water may have contributed to the contamination. It becomes more concerned to detect that the set of bacterial isolates in this study were similar to those documented to proliferate in leachate samples as reported by Odeyemi et al. (2011). This however could be traceable to the proximity of these water bodies to dumpsites, through which these contaminant may have find their ways into the water via percolation, seepage or run-off; as narrated by the report of Odeyemi et al. (2012).

Antibiotic sensitivity results shows that majority or almost all the bacteria isolated were resistant to the various antibiotics used. This is in support with the report of Odeyemi et al. (2010) which stated that up to about $80 \%$ of the coliform found in the ground water is resistant to antibiotics. The mechanisms used by these organisms include: modification of the target site, change in bacteria cell membrane, production of enzymes which inactivates the drug, reduction in the cellular uptake of drugs and rapid extrusion of the antibiotics. These mechanisms arise when bacteria are subjected to genetic changes as a result of mutation or by acquisition of a new genetic material (Prescott et al., 2008).

The high rate of antibiotics resistance by the Escherichia coli isolates in this study correlates with the work of Odeyemi et al. (2013) which reported the resistance of Escherichia coli to about seven of the eight antibiotics used. The multiple resistance pattern of the Escherichia coli isolates as shown in the antibiotics testing also agrees with the findings of Heike and Reinhard (2005); Walsh et al. (2005) which also reported the growing discoveries of antibiotics resistant strains and attributed this to the use of antibiotics in animal husbandry which has caused genotypic change due to chromosomal mutation. Some microorganisms that are found in the soil find their way into the water bodies through the surface run off and because many of these soil microorganisms have the 
ability to produce antibiotics normally, they acquire some mechanisms that can render these antibiotics ineffective hence, they have no effects on them when they are used (Akonai, 2003). Another way by which these isolated bacteria can develop resistance to the various antibiotics is through the transfer of antibiotic resistant gene from one organism to another.

Three isolate (E. coli, Pseudomonas aeruginosa, and Staphylococcus aureus) were selected among the plasmid mediated bacteria for curing after been subjected to antibiotic sensitivity test with the aim curing the plasmids contained in the bacteria according to the method of Brown (2000). After been subjected to curing, Pseudomonas aeruginosa that exhibited plasmid resistance ceftazidine (CAZ), cefuroxime (CRX), Augmentin (AUG) and cefotaxime (CTX) became susceptible to Augmentin (AUG) after the plasmid has been cured, but still maintain resistant ability against ceftazidine (CAZ), cefuroxime (CRX), and cefotaxime (CTX). Staphylococcus aureus that was resistant to gentamicin (GEN), cefuroxime (CRX), augmentin (AUG), cefotazine (CXC), erythromycin (ERY), ceftazidine (CAZ) and ceftriazole (CTR) also became susceptible to ceftriazole (CTR) after been cured. E. coli25 that exhibited plasmid resistance to ceftazidine (CAZ), cefuroxime (CRX), cefotaxime (CTX), and augmentin (AUG) still remained unchanged even after the plasmid has been cured, this could be as a result of mutation or acquisition of new genes.

The resistant pattern of the isolates (E. coli, Pseudomonas aeruginosa, and Staphylococcus aureus) was confirmed by subjecting the cured isolate to antibiotic susceptibility testing using the same antibiotics. The three (3) bacteria isolates (E. coli, Pseudomonas aeruginosa, Staphylococcus aureus) had no plasmid recovered after been subjected to curing which indicate that plasmid has been lost during the process of curing as described by (Vivyan et al., 1972).

\section{Conclusion and recommendations}

This present study revealed that the sources of water in the Ekiti South Senatorial district are not safe for drinking especially because of the incidence and abundance of MAR bacteria in water sources. Serious health hazards could result from consumption of such water. Hence, proper and adequate treatment of this water is highly required. Human attitudes such as dumping of refuse or untreated sewage and defecating in and around water bodies should also be discouraged

This study recommends the provision of portable water, modern sanitary sewage disposal facilities and creation of awareness to the people in the community of the risk associated with the consumption of contaminated water. Also, sewage and refuse should not be dumped into the stream water around the landfill site in order not to increase the nutrient availability of the water which will aid growth of microbes in water bodies. Further molecular characterization of the isolates is recommended to ascertain identity and other genetic factors that determined the multiple resistances of the microbes

\section{References}

[1] Figueras, M. J. and Borrego, J. J. (2010). New perspectives in monitoring drinking water microbial quality. Int. J. Environ. Res. Public Health 7, 4179-4202. https://doi.org/10.3390/ijerph7124179.

[2] Birnboim, H. C. and Doly, J. (1979). A rapid alkaline procedure for screening recombinant Plasmid DNA. Nucleic Acid Res. 7: 15131523. https://doi.org/10.1093/nar/7.6.1513.

[3] Kado, C. I and Liu, S. T. (1981). Rapid procedure for detection and isolation of large and small plasmids. J. Bacteriol. 145: 1365-1373.

[4] Datta, N., Hadges, R. W., Shaw, E. J., Sykes, R. B. and Richman, M. H. (1971). Properties of an R- factor from Pseudomonas aeruginosa. J. Bacteriol. 108: 1244-1249.

[5] Brown, T. A. (2000). Essential Molecular Biology, A Practical Approach. Oxford University Press. $\quad 2^{\text {nd }}$ Edition. Pp 69-102.

[6] APHA (1985). Standard Methods for Examination of Water and Wastewater, 20th Edition, American Public Health Association, Washington D. C.
[7] APHA (1998). Standard Methods for the Examination of Water and Wastewater, 20th edition. American Public Health Association, Washington, D.C.

[8] Trivedy, R. K.and Goel, P. K (1986). Chemical and biological methods for water pollution studies, Environmental Publication, Karad, Maharashtra.

[9] Akonai, A. K., Lamikanra, A. and Ola, J. B (2003) Transmissible thrimethoprim resistance of strains of Escherichia coli. From cases of infantile diarrhea. Journal of medical microbiology. 32(7): 159-162.

[10] Alexandra, P. (2008). Evaluation of Ground water quality of Mobi town in Adamawa state, Nigeria.Afr Journal of Biotech, 7:17121715. https://doi.org/10.5897/AJB08.227.

[11] Brown, T. A (2010). "Chapter 2 - Vectors for Gene Cloning: Plasmids and Bacteriophages". Gene Cloning and DNA Analysis: An Introduction. Wiley-Blackwell. 10(1): 17-18.

[12] Cheesbrough, M. (2004). District Labor-atory Practice in Tropical Countries (part ii). Cambridge University Press. Pp 50-150.

[13] CLSI (2005). Performance standards for antimicrobial susceptibility testing; fifteenth informational supplement, Clinical and Laboratory Standard Institute Wayne, Pa. M100-S15, 25(1): 13-17.

[14] Edama, M. D., Omemu, A. M and Fapetu, O. M (2001). Microbiological and Physiochemical Analysis of Different Sources of Drinking Water in Abeokuta, Nigeria. Niger. J. Microbial, 15(1): 57-61

[15] Environmental Protection Agency (2002). Drinking Water, National Primary Drinking Water Regulations: Total Coliforms (including fecal and E.coli). Fed.Regist, 54(124): 27544.

[16] Heike, V. and Reinhard, M. (2005). Antimicrobial Resistance of Escherichia coli and Therapeutic Implications. Int. J. Med. Micro$\begin{array}{lll}\text { biol. } & \text { 295(6-7): } & \text { 503-511. }\end{array}$ https://doi.org/10.1016/j.ijmm.2005.07.002.

[17] Holt, J. G., Krieg, N. R., Sneath, P. H. A., Staley, J. T. and Williams, S. T. (1994). Bergey's manual of determinative bacterial. Baltimore, Ninth Edition, Williams and Wilkins, London, UK, 787.

[18] Kaper, D. M. and Roane, T. M. (2004). Differential responses of a mine tailings Pseudomonas isolate to cadmium and lead exposures. Biodegradation, 17 (4), 379-387.

[19] Makinde, A. M. and Akande, F. I. (2012). Effects of Lead and Simulated Acid Rain on Chlorophyll Contents of Selected Trophical Mosses. Ife Journal of Science, 14(2):309-313.

[20] Nicholas, E. J., Andrew, R. P. and James, M. B. (2009). Evaluation of a Simple Method to Classify the Thermal Characteristics of Streams using a Nomogram of Daily Maximum Air and Water Temperatures. North American Journal of Fisheries Management 29:1605-1619. https://doi.org/10.1577/M08-251.1.

[21] Odeyemi, A. T. and Agunbiade, R. O. (2012). Bacteriological and metal analyses of Water samples from Awotunde fish pond and river. Scientific Journal of Microbiology, 1(2): 48-54.

[22] Odeyemi, A. T., Ajayi, A. O. and Igbalajobi, O. A (2013). Plasmid profile of isolated bacteria from Arinta water fall in Ipole-iloro, Ekiti State. Journal of microbiology research, 3(1):32-38.

[23] Odeyemi, A. T., Dada, A. C., Ogunbanjo, O. R. and Ojo, M. A. (2010). Bacteriological, physiochemical and mineral studies on Awedele spring water and soil samples in Ado-Ekiti, Nigeria. African Journal of Environmental Science and Technology, 4(6):319327. https://doi.org/10.5897/AJEST09.194.

[24] Odeyemi, A. T., Faweya, E. B., Agunbiade, O. R. and Ayeni, S. K. (2011). Bacteriological, Mineral and Radioactive Contents of Leachate Samples from Dump Sites of Ekiti State Government Destitute Center in Ado Ekiti. Archives of Applied Science Research, 3(4): 92-108.

[25] Okonko, I. O., Adejoye, O. D., Ogunnusi, T. A., Fajobi, E. A. and Shittu, O. B. (2008). Microbiological and Physiochemical Analysis of Different Water Samples used for Domestic purposes in Abeokuta and Ojata, Lagos State, Nigeria. African Journal of Biotechnology, 7(5):617-621.

[26] Olutiola, P. O., Famurewa, O. and Sonntag, H. G. (2001). An introduction to General Microbiology. A Practical Approach. Cad Heideberg Virlag Sanstaltund Druckerei Gmbh Helderberg, Germany, pp. 38-51.

[27] Prescott, M. L., Harley, P. J. and Klein, A. D. (2008). Microbiology. 8th Edition. McGraw Hill Companies Inc. New York.

[28] Roohul, A., Syed, S. A., Zubair, A. and Jabar, Z. K. (2012). Microbial Analysis of Drinking Water and Water Distribution System in New Urban, Peshawar. Current Research Journal of Biological Science, 4(6): 731-737.

[29] Schlegel, H. G. (2002). General Microbiology. $7^{\text {th }}$ Ed. Cambridge University Press. 480p. 
[30] Vivyan, E., Hedges, R. W. and Datta, N. (1972). Two modes of curing transmissible bacterial plasmids. J. Gen. Microbiol., 70, 443 - 452. https://doi.org/10.1099/00221287-70-3-443.

[31] Walsh, C., Duffy, G., O’mahony, R., Faning, S., Blain, I. S. and McDowell, D. A. (2005). Antimicrobial Resistance in Irish Isolates of Verocytotoxigenic Escherichia coli VTEC. Int. J. Food Microbiol, $109(3)$ : 173-178. https://doi.org/10.1016/j.ijfoodmicro.2006.01.023.

[32] Wasteson, Y., Garvey, P., McDowell, D. A., Cola, J. and Duffy, G. (2001). Control of Verocytogenic E.coli. Special edition of Int. J. Food Microbiol. 66: 1-2.

[33] World Health Organization (WHO), (2006). Guidelines for Drinking Water Quality Vol. 1 Geneva, Switzerland.

[34] Yagoub, A. E. A. and Ahmed, T. A (2010). Microbiological evaluation of the quality of tap water distributed at Khartoum state. Science alert.

[35] Zamxaka, M., Pironcheva, G. and Zamxaka, N. Y. O. (2004). Bacterial Community Patterns of Domestic Water Sources in the Gogogo and Nkonkobe Areas of the Eastern Cape Province, South Africa. Water SA, 30(3): 341-346. https://doi.org/10.4314/wsa.v30i3.5082. 